\title{
Optimization of Pulsation Rate of the Milking System for the Mammary Gland Remodeling during Involution in Thai Crossbred Holstein Cows
}

\author{
A. Tiantong ${ }^{\mathrm{a},}{ }^{,}$, K. Sasiwimonrit ${ }^{\mathrm{a}}$, S. Saengwong ${ }^{\mathrm{b}}$, W. Inyawilert ${ }^{\mathrm{c}}$, A. Chaokaur ${ }^{\mathrm{a}}$, \& S. E. Chen ${ }^{\mathrm{d}}$ \\ ${ }^{a}$ Faculty of Animal Sciences and Agricultural Technology, Silpakorn University, \\ Phetchaburi IT Campus, Phetchaburi 76120, Thailand \\ 'Division of Animal Science, School of Agriculture and Natural Resources, University of Phayao, \\ Phayao 56000, Thailand \\ 'Department of Agricultural Science, Faculty of Agriculture, Natural Resources, and Environment, Naresuan University, \\ Phitsanulok 65000, Thailand \\ dDepartment of Animal Science, National Chung Hsing University, Taichung 402, Taiwan \\ *Corresponding author: tiantong_a@su.ac.th \\ (Received 15-06-2020; Revised 11-08-2020; Accepted 13-08-2020)
}

\begin{abstract}
This study aimed to investigate the effects of pulsation rate of the milking machine on the proteinous components and gelatinase activity in the mammary secretion for optimal tissue remodeling during the dry period in tropical dairy cows. Nine healthy primiparous Thai crossbred Holstein cows $(75 \% \mathrm{HF})$ were milked with various pulsation rates $(50,60$, and 70 cycles $/ \mathrm{min})$ one week after calving. The total protein contents of the secretions increased along the time course in 50 and $60 \mathrm{cycles} / \mathrm{min}$ groups but not in 70 cycles/min group and were not different among the 3 groups along the time course. Lactoferrin and BSA abundance of the 3 groups as well as $\gamma$-globulin in 50 and 70 cycles/min groups also increased in a time-dependent manner, in which only $\gamma$-globulin abundance in 60 cycles/min group 14 days before drying off and lactoferrin in 50 cycles/min group 14 days after drying off were significantly higher than those of the other 2 groups. In tissue remodeling by gelatinase activity analysis, 50 cycles/ min group showed dramatic increases of Matrix metalloproteinase-9 (MMP-9) and MMP-2 activities after drying off, whereas 60 and 70 cycles/min groups had a significant but a smaller change $(p<0.05)$ along the time course. Cows with 60 cycles/min exhibited dramatic increases of MMP-9 and MMP-2 activities than the other groups before drying off $(\mathrm{p}<0.05)$. The findings suggested that milking pulsation rate at 60 cycles/min resulted in higher activity of remodeling during mammary involution and thus may benefit the renewal and health of the udder in the long run.
\end{abstract}

Keywords: pulsation rate; extracellular matrix; mammary gland; drying off; Thai crossbred dairy cows

\section{INTRODUCTION}

The milking pulsation can affect milk yield and also the health of the udders. Any adverse effects on either of these factors would negatively influence profits. An optimal pulsation rate is able to control congestion and the onset of edema in the teat tissue and further reduce the rate of new intramammary infection rate (IMI) (Mein, 2012). Several studies have investigated the effects of pulsation rates on the health of the udders (Ferneborg \& Svennersten-Sjaunja, 2015; Romero et al., 2020), as well as the teat end conditions (Besier \& Bruckmaier, 2016). An increase of new infection rate was reported in pulsation failure, such as the absence of pulsation (Besier et al., 2016), and insufficient duration of liner closure (Penry et al., 2018) or of d-phase pulsation (Upton et al., 2016). Past studies showed a worsening status of the udder health with pulsation rates of 90 and 120 cycles per min (Atigui et al., 2015) or lower than 55 cycles per min (Osteras et al., 1995).

Drying off in dairy cows results in changes in the composition and functionality of the secretion retained in the udder cisterns. In the initial stages after drying off, blood proteins are transferred into the alveolar lumen, by which the concentrations of bovine serum albumin as well as the milk immunoglobulins are significantly enhanced (Hurley \& Theil, 2011; Tiantong et al., 2015b). These alterations are believed to arise as a consequence of transport facilitation or due to the loss of integrity at the junctions connecting mammary epithelial cells (Stelwagen \& Singh, 2014). Besides, there is a spontaneous change in the relative abundance of the main milk proteins (Tiantong \& Mwabena, 2019). Although such observations have been made, the effects of pulsation rate of milking machine on the alterations of milk components during the involution of the mammary gland have not been well studied.

The extracellular matrix (ECM) forms a milieu surrounding cells that reciprocally influences cellular function (Hynes, 2009). Matrix metalloproteinases (MMP) function as selective enzymes to cleave proteinous components, notably ECM or chemokine peptides (Khokha \& Werb, 2011), and thus are tightly related to the process of remodeling, especially when the damaged 
tissues undergo repairing processes in the case such as inflammation. The activity of MMP is tightly controlled on various levels, including the transcription, the secretion, and the post-secretion activation (Li et al., 2016).

When the mammary glands become inflamed, especially at early phase of the dry period of the dairy cattle, the neutrophil levels in somatic cells can rise long before any increase in the other cell types (Pezeshki et al., 2010; Yu et al., 2012). In vitro studies demonstrated a dramatic but transient increase of MMP-9 due to the neutrophils infiltration in the mammary secretions of freshly dry dairy cattle (Yu et al., 2011). Therefore, it can be inferred that the high levels of MMP-9 found in the early dry secretions of dairy cattle can reflect the procession and physiological significance during milk stasis (Gifre-Renom et al., 2020).

The study aimed to examine the effect of three pulsation rates, 50, 60, and 70 cycles/min, that are frequently used by the smallholder dairy farmers in Thailand, on the abundance of protein components and ECM degradation of the mammary secretions in respect to gelatinase activity for remodeling progression in Thai crossbred Holstein cows.

\section{MATERIALS AND METHODS}

\section{Animals and Experimental Design}

Nine healthy primiparous Thai crossbred Holstein cows $(n=9 ; 75 \% \mathrm{HF})$ were chosen from the herd at the Silpakorn University Phetchaburi IT Campus dairy farm in Phetchaburi Province, Thailand. These cows were randomly divided into three groups with different milking pulsation rates; 50, 60, and 70 cycles per min in a pulsation ratio $60: 40$, throughout the lactation period (280 $\pm 30 \mathrm{~d}$ in milk) with negative CMT (California mastitis test) results and no signs of intramammary infection. One week after calving, cows were milked twice daily at 0600 and $1630 \mathrm{~h}$ with milking machines at different pulsation rates. During the lactation period, cows were fed on a total mix ration (TMR); 3,300 kcal/ $\mathrm{kg}$ metabolizable energy, and $20 \%$ crude protein. When milk yields were less than $5 \mathrm{~kg} / \mathrm{d}$ with more than $280 \pm$ 30 days in milking (DIM), cows were moved to milkstasis stalls and fed twice per day with a $2500 \mathrm{kcal} / \mathrm{kg}$ metabolizable energy, $14 \%$ crude protein, and rice straw and water were provided ad libitum throughout the period of sample collection within two weeks. The experimental design and sampling protocols were approved by the Animal Use and Care Committee of the Faculty of Animal Sciences and Agricultural Technology, Silpakorn University under approval number Asat.SU 031/2562, based on the Ethics of Animal Experimentation of the National Research Council of Thailand.

\section{Sampling Processes and Preparation of the Samples}

Milk samples ( 25 mL) were manually collected from individual quarters of each cow 14 days (d -14) and 7 days $(\mathrm{d}-7)$ prior to the expected drying-off and the day before dry-cow therapy (d 0), and 3 days (d 3), 7 days (d 7), and 14 days (d 14) after dry-off. Collected milk was skimmed by $400 \times g$ at $4^{\circ} \mathrm{C}$ for 20 minutes in order to collect the clear supernatant. The supernatant, free of fat and cells, was then placed in aliquots under $-20^{\circ} \mathrm{C}$ until further analyses within a two-months (Tiantong et al., 2015a).

The protein concentration of skimmed supernatants was determined using a dry-binding reagent (Bio-Rad Laboratories, Hercules, CA, USA) in a microplate format (SPECTROStar Nano, BMG Labtech $\mathrm{GmbH}$, Ortenberg, Germany) with BSA (Sigma-Aldrich) as a standard. A standard curve was plotted for quantification of SDSPAGE analysis and gelatin zymography.

\section{Gel Electrophoresis (SDS-PAGE)}

The proteinous components of milk were identified by $9 \%$ of resolving gel in SDS-PAGE system of Laemmli (1970). Briefly, aliquots of the skimmed milk supernatants equivalent to $10 \mu \mathrm{g}$ protein content were treated with 2X Native Sample Buffer (161-0738, BioRad Laboratories, Hercules, CA, USA) before loading. Afterward, gels were stained for $1 \mathrm{~h}$ with the Coomassie Brilliant Blue R-250 staining solution (161-0436, BioRad Laboratories, Hercules, CA, USA) and washed with distilled water until clear visualization. The respective band image was captured with Epson Stylus TX130 (Seiko Epson Corporation, Nagano, Japan) and then measured by Image J software (v. 1.50; National Institutes of Health, Bethesda, MA, USA). Adjustment of the integrated band zone then took place to take total protein loading into consideration.

\section{Gelatin Zymography}

Gelatin zymography was performed under native SDS-PAGE conditions, whereby the resolving gel made use of gelatin to serve as the substrate. MMP-2 and -9 were identified on the molecular size of gelatinolytic band at $37{ }^{\circ} \mathrm{C}$ as described previously (Piamya et al., 2015). Briefly, the skimmed milk supernatants of $20 \mu \mathrm{g}$ total proteins were first mixed with a zymogram sample buffer (161-0764, Bio-Rad Laboratories, Hercules, CA, USA), and then was subjected to $7.5 \%$ native SDS-PAGE, with $0.1 \%$ gelatin obtained from bovine skin (SigmaAldrich) within the resolving gel. The gels then underwent further incubation using a renaturing solution of $2.5 \%(\mathrm{v} / \mathrm{v})$ Triton-X100 (Sigma-Aldrich) for 30 minutes at room temperature while completely dripped using distilled water. Additional incubation then took place at a temperature of $37^{\circ} \mathrm{C}$ for $19 \mathrm{~h}$ in zymogram development buffer (161-0766, Bio-Rad Laboratories, Hercules, CA, USA) for gelatinolytic activity. Subsequently, the gels underwent staining with $0.5 \%$ coomassie brilliant blue R-250 (161-0400, Bio-Rad Laboratories, Hercules, CA, USA) for 30 minutes, and were then destained for $30 \mathrm{~min}$ in the destaining solution containing 30\% methanol, $7.5 \%$ glacial acetic acid, and $62.5 \%$ distilled water twice, prior to final preservation in the form of clear bands which were visible against the blue background. The MMP-2 and -9 levels were presented as the area of the band, which was captured by the Epson Stylus TX130 (Seiko Epson Corporation, Nagono, Japan) before integration with Image J software, version 1.50 (National Institutes of Health, Bethesda, MA, USA). 


\section{Statistical Analyses}

Data of total protein concentration, proteinous components, and MMP-proteolytic capacities were analyzed using the GLM procedure and Duncan's new multiple range tests (R Core Team, 2018) with sampling time (14 days and 7 days before drying off, and on the day of drying off and 3, 7, or 14 days after drying off) and the different pulsation rates $(50,60$, or 70 cycles per min) as the major factors. Interaction between sampling time and the different pulsation rates were also assessed. All results were presented as mean \pm SE. Statistical significance was considered at $\mathrm{p}<0.05$.

\section{RESULTS}

\section{Total Protein Concentration}

Cows with pulsation rates at 50 and 60 cycles/min, but not at 70 cycles/min, showed a time-dependent increase of total protein concentrations, particularly on 7 days and 14 days after drying-off. However, the total protein concentrations were not significantly different among cows with different pulsation rates (Figure 1).

\section{Protein Composition}

Typical images of the semi-quantitative SDS-PAGE in the case of skimmed supernatants from mammary secretions can be observed in Figure 2 (A). The SDS-PAGE image of supernatant of mammary secretion samples showed a characteristic increase of band intensity corresponding to of $\gamma$-globulin, lactoferrin, and BSA from 14 days before milk stasis until 14 days after drying off period, while the band intensity of caseins increased from 14 days before milk stasis until the day of drying off then slightly decreased until 14 days after drying off therapy.

It was found that the mean values along with standard error (SE) for the quantity of $\gamma$-globulin in the supernatant of the mammary secretions were significantly $(\mathrm{p}<0.05)$ greater 14 days before milk stasis of cows with pulsation rate at 60 cycles/min than that of cows with pulsation rates at 50 and 70 cycles/min (Figure 2B). However, the abundance of $\gamma$-globulin of cows with pulsation rates at 50 and 70 cycles/min increased significantly along the time course, but not in cows with 60 cycles/min (Figure 2B).

The mean of the abundance of lactoferrin was significantly $(p<0.05)$ reduced in those cows which had pulsation rates of 60 cycles per minute compared to those at 50 cycles/min 14 days after drying off period. Also, the abundance of lactoferrin in the 3 groups increased along the time course with top levels 14 days after drying off and the lowest levels 14 days before drying off period.

The mean of the abundance of BSA in mammary supernatant was not significantly different among the 3 groups. Similar to lactoferrin, BSA abundance in the 3 groups increased along the time course with a top 14 days after drying off and the nadir 14 days before drying off. For cows with 50 cycles/min pulsation rate, the abundance of caseins increased to 3 days after drying off period and then decline, while the casein content of cows with 60 cycles/min pulsation rate remained constant until a quick drop 14 days after drying off period and cows with 70 cycles/min showed an increase to the day of dry off period and then a constant decreased level on 14 days after drying off period. The proteins which are typical for the dry period, $\gamma$-globulin, lactoferrins, and BSA, showed the most significant changes from 3 days to 14 days in milk stasis.

\section{Matrix Metalloproteinase-2 and -9 (MMP-2, -9)}

Figure 3 presents the gelatin zymograms of the supernatants of skimmed mammary secretions. It was possible to detect both MMP-2 and MMP-9 in the secretions of cows with a pulsation rate at 50,60, and 70 cycles/min during the dry period. The means of MMP-9 activity in cows at 60 cycles/min had a top level on 14

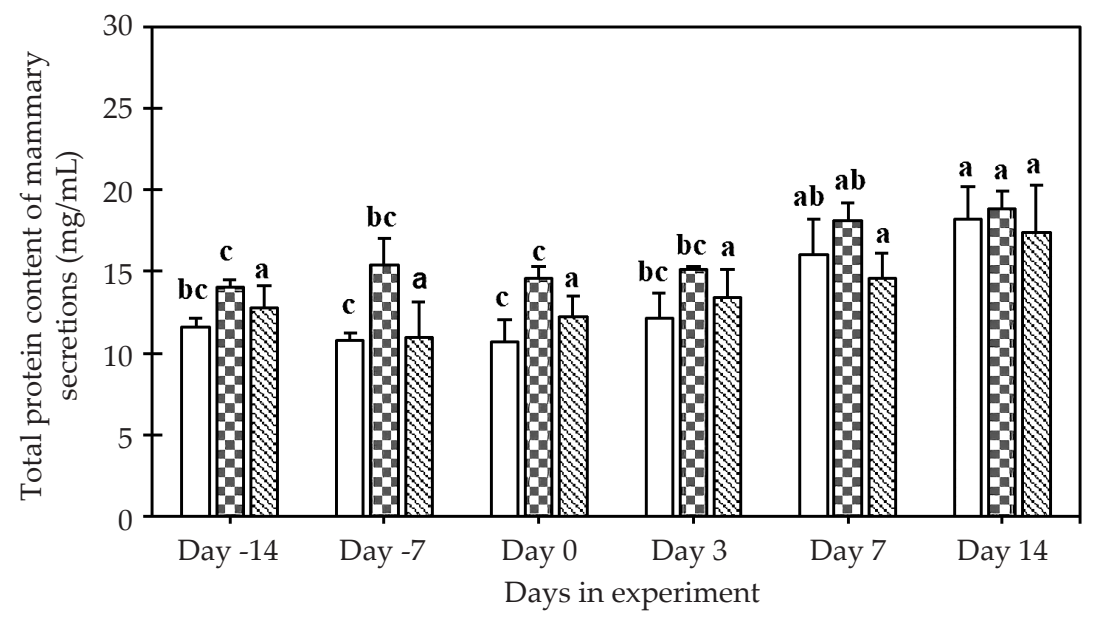

Figure 1. Total protein concentration of mammary secretion supernatant of the experimental Thai crossbred Holstein cows during the dry period with the differential pulsation rates, including 50 cycles/min; 60 cycles/min, and 70 cycles/min. ${ }^{a-c}$ Values with different superscripts differ significantly $(\mathrm{p}<0.05)$ among days in experiment within the same animal.

$\square=50$ cycles $/ \mathrm{min} ; \mathbf{D}=60$ cycles $/ \mathrm{min} ; \mathbf{Q}=70$ cycles $/ \mathrm{min}$. 

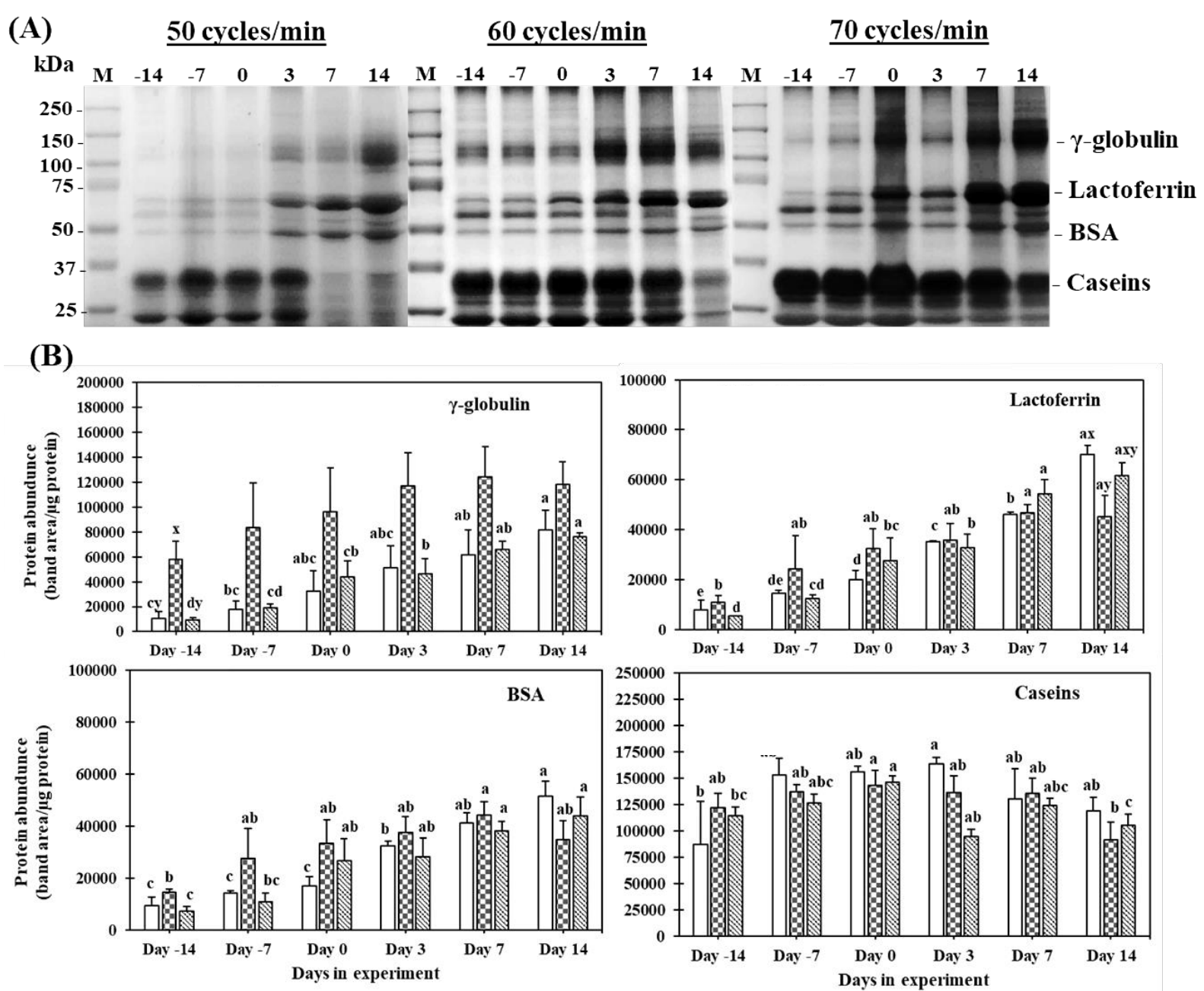

Figure 2. (A) SDS-PAGE images and (B) the abundance of protein composition of the mammary secretion supernatant of the experimental Thai crossbred Holstein cows during the dry period with the differential pulsation rates, including 50 cycles/min; 60 cycles/min, and 70 cycles/min. ${ }^{\text {a-c } V a l u e s ~ w i t h ~ d i f f e r e n t ~ s u p e r s c r i p t s ~ d i f f e r ~ s i g n i f i c a n t l y ~}$ $(p<0.05)$ among days in experiment within the same animal. ${ }^{x-z}$ Values with different superscripts differ significantly $(\mathrm{p}<0.05)$ in various levels of pulsation rate within the same day in experiment.

$\square=50$ cycles $/ \mathrm{min} ; \mathbf{Q}=60$ cycles $/ \mathrm{min} ; \mathbf{\$}=70$ cycles $/ \mathrm{min}$.

days before milk stasis and then declined on the day of dry off, then increased 3 days again after drying off period and finally reach a nadir 14 days after drying off period ( $\mathrm{p}<0.05$ ). In cow with 50 or 70 cycles/min, MMP-9 activity increased along the time course to reach a top 7 days after drying off period and then declined slightly 14 days after drying off period $(\mathrm{p}<0.05)$, in which MMP9 levels during the milk stasis stage ( 3 days and 14 days after drying off period) were significantly higher than those before drying off period $(p<0.05)$.

Before milk stasis (14 and 7 days before and at the day of drying off period), MMP-9 activities were significantly higher $(\mathrm{p}<0.05)$ in the case of cows which had pulsation rates of 60 cycles per minute compared to those with 50 and 70 cycles/min. After milk stasis, the MMP-9 level was ranked as $70>60>50$ cycles/min 3 days after drying off period, and 50=70>60 cycles $/ \mathrm{min} 7$ days and 14 days after drying off period $(\mathrm{p}<0.05)$.

The means of MMP-2 activity of cows with pulsation rate at 50 cycles/min increased with time course to reach a top 3 days after drying off period and then de- clined 14 days after drying off period, in which MMP-2 levels after the milk stasis stage (3 days to 14 days after drying off period) were significantly higher than those before dry-off $(\mathrm{p}<0.05)$. The MMP-2 level in cows with 60 cycles/min decreased on the days of milk stasis, then increased 3 days after drying off period, and finally declined to the nadir 14 days after the drying off period, whereas cows with 70 cycles/min exhibited a constant MMP-2 activity 3 days before milk stasis and then declined to the nadir 14 days after the drying off period $(\mathrm{p}<0.05)$. The MMP-2 activity was ranked as $50<60=70$ cycles/min 14 days and 7 days before drying off period, $50<60<70$ cycles/min on the day of milk stasis, $50>70>60$ cycles/min 3 days after drying off period, $60>50=70$ cycles/min 7 days after drying off period, and $60<50=70$ cycles/min 14 days after drying off period $(p<0.05)$.

\section{DISCUSSION}

Based on the protein components and MMP activity in the milk secretions, it appears that milking with 


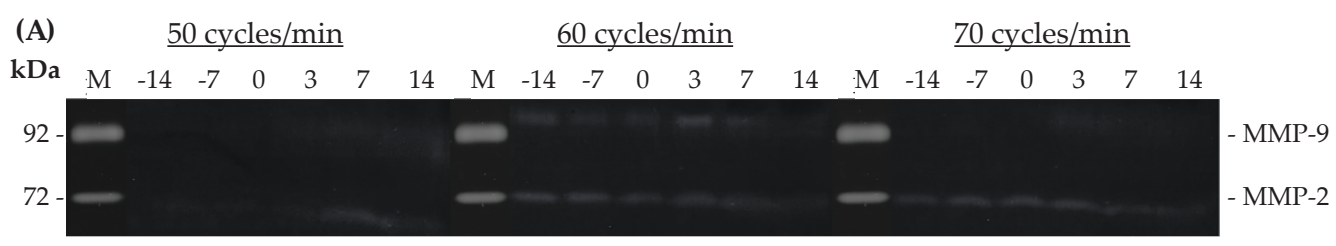

(B)
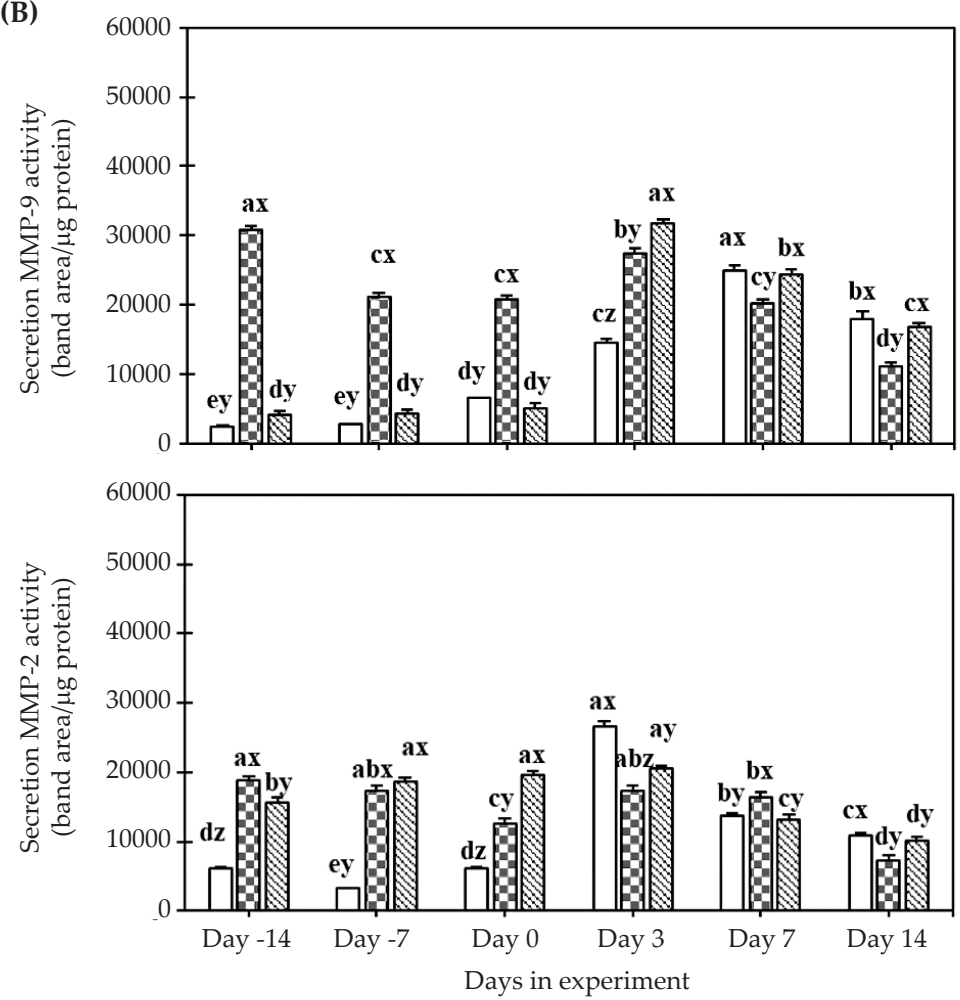

Figure 3. (A) Gelatin zymography images and (B) the gelatinolytic activity abundance of the mammary secretion supernatant of the experimental Thai crossbred Holstein cows during the dry period with the differential pulsation rates, including 50 cycles $/ \mathrm{min} ; 60 \mathrm{cycles} / \mathrm{min}$, and $70 \mathrm{cycles} / \mathrm{min}$. $^{\mathrm{a}-}$ ${ }^{c}$ Values with different superscripts differ significantly $(p<0.05)$ among days in experiment within the same animal. ${ }^{x-z}$ Values with different superscripts differ significantly $(p<0.05)$ in various levels of pulsation rate within the same day in experiment.

$\square=50$ cycles $/ \mathrm{min} ; \mathbf{Q}=60$ cycles $/ \mathrm{min} ; \mathbf{B}=70$ cycles $/ \mathrm{min}$.

pulsation rate at 60 cycles/min can optimize the mammary gland remodeling during involution. Pulsation is defined as the cyclic opening and closing of the teat cup liner, which is an important factor in dairy cattle farm productivity. In Thailand, it is common to use alternating pulsation at a rate of 60 cycles/min for which the ratio is 60:40 for the front to rear cups on the teats. This arrangement is widely used by dairy farmers because they believe it is a good compromise by the system to provide both speed milking and better udder health. As milk yields per cow continue to increase and, therefore, milking times per cow become longer, an optimal combination of pulsator setting might change to a rate of 55 cycles/min in a ratio of 65:35. Besides, some farmers in Thailand also recommend that the pulsation rate can be increased up to 75 cycles/min to increase milk harvest and reduce the milking time without the new IMI. However, current quantitative recommendations for milking machine installation for Thai crossbred Holstein cows showed no specification for the pulsation characteristics, given the absence of any studies regard- ing to these features with infection risk and mammary gland remodeling during the dry period. In this study, three different pulsation rates (50, 60, and 70 cycles/min) as widely used in Thailand were tested to optimize the pulsation rate for the smallholder dairy farms. The present results showed no differences in total protein concentration of milk by the 3 pulsation rates. These results are consistent with the previous works by Tromas et al. (1991), who showed no differences in milk composition such as fat and protein percentage, or somatic cell count due to pulsation rate at the same level. Meanwhile, Ferneborg \& Svennersten-Sjaunja (2015) reported that the pulsation rate of 60 cycles/min with the $60: 40$ ratio increased milking efficiency in automatic milking system and had no negative effects on teat condition or milk somatic cell counts.

Besides, we found that the total protein concentration steadily increased until 14 days after drying off. According to our period works (Tiantong et al., 2015b; Tiantong \& Mwabena, 2019), this increase is primarily attributed to the increased concentrations 
of immunoglobulins, serum albumin, and lactoferrin. Also, this increase can be attributed to the decreased mammary gland functionality in the first two weeks of the dry period, with alterations in mammary secretion components due to the decreased synthesis of casein (Raimondo et al., 2013), and changes in cell junctions and vascular permeability by the increased protein concentration from blood serum (Boutinaud et al., 2003).

Examination of relative abundance of the main proteins in the mammary secretions was achieved through the biochemical methodology SDS-PAGE, but this was not the case for absolute concentration. In drying off mammary secretions, there is an almost reciprocal change in the ratios of $\gamma$-globulin, lactoferrins, and BSA (Chen et al., 2007; Ho et al., 2010). There are two possible reasons for the lowering of the casein proportion. These are acceleration of caseinolysis (Nielsen, 2002; Ferranti et al., 2004) and the attenuation of the synthesis of casein (Miller et al., 2006; Sorensen et al., 2006). In contrast, a rise in the BSA fraction might be partially linked to the heightened permeability of the blood-mammary gland barrier (Wenz et al., 2010). One early sign of mastitis is high levels of BSA in milk (Wenz et al., 2010). The situation for milk $\gamma$-globulin and lactoferrins differs from BSA due to endogenous origins; they can be considered as marker proteins which indicate mammary gland involution, since they usually appear in high proportions following the drying off period (Ho et al., 2010).

The normal kind of reciprocal shift in the prevalence of casein-like bands and lactoferrin-like bands were observed in the SDS-PAGE, in which cows with pulsation rate at 60 cycles/min showed an earlier occurrence than those with 50 and 70 cycles/min (Figure 2), which is indicative of a rapid decline in the synthetic capacity of the milk.

The turnover of mammary epithelial cells accelerate the early dry period in dairy cattle (Khokha \& Werb, 2011), although the extent of the breakdown of the mammary architecture was so trivial as to be invisible via morphological or histological technology (Sorensen et al., 2006). MMP has been employed for organ remodeling in the case of diseases such as Osteoarthritis as a result of its potential for ECM degradation (Maldonado \& Nam, 2013). It has also been effective for cow mastitis (Li et al., 2016) and also in dairy cattle which are in drying-off period (De Vries et al., 2010). The particular units of MMP-9 in the milk rise as lactation progresses in dairy cattle, or after milk stasis (Chen et al., 2007; Weng et al., 2008; Yu et al., 2012). In this work, the increase in MMP-9-specific units was observed at an earlier stage in the milk secretions of the cows which had a pulsation rate at 60 cycles/min quarters than those with pulsation rate at 50 and 70 cycles/min quarters (Figure 3). However, specific units of MMP-2 which were almost constant could be seen in those cows with both 60 and 70 cycles/min quarters throughout the experiment period (Figure 3).

Our observations of MMP-2-specific units found in the secretions of quarters at various pulsation rates along the drying off progression can solidify the endogenous aspects of mammary tissue, which confirms the earlier results for MMP-9 results. It can therefore be inferred that the ECM for those quarters which involved pulsation rates of 60 cycles/min would show a greater degradation as a consequence of the enhanced PMN chemotaxis as well as the related release of MMP-9.

\section{CONCLUSION}

The milking machine with pulsation rate at 50, 60 , or 70 cycles/min did not affect total milk protein, whereas the pulsation rate at 60 cycles/min may promote mammary gland remodeling process during early involution, and thus may reduce the risk of new IMI. Accordingly, the rate of pulsation of 60 cycles $/ \mathrm{min}$ is recommended to increase milking efficiency in automatic milking systems without damaging the mammary tissues.

\section{CONFLICT OF INTEREST}

The authors hereby declare that no conflict of interest exists of a personal or financial nature with any other person or organization, in the context of the contents of the manuscript presented.

\section{ACKNOWLEDGEMENT}

The authors wish to express sincere gratitude for the financial assistance provided by the Faculty of Animal Sciences and Agricultural Technology, Silpakorn University, Thailand.

\section{REFERENCES}

Atigui, M., P.G. Marnet, A. Barmat, T. Khorchani, \& M. Hammadi. 2015. Effects of vacuum level and pulsation rate on milk ejection and milk flow traits in Tunisian dairy camels (Camelus dromedarius). Trop. Anim. Health Prod. 47: 201-206. https://doi.org/10.1007/s11250-014-0708-0

Besier, J., \& R.M. Bruckmaier. 2016. Vacuum levels and milkflow-dependent vacuum drops affect machine milking performance and teat condition in dairy cows. J. Dairy Sci. 99: 3096-3102. https://doi.org/10.3168/jds.2015-10340

Besier, J., O. Lind, \& R.M. Bruckmaier. 2016. Dynamics of teatend vacuum during machine milking: types, causes and impacts on teat condition and udder health - a literature review. J. Appl. Anim. Res. 44: 263-272. https://doi.org/10.1 080/09712119.2015.1031780

Boutinaud, M., C. Rousseau, D.H. Keisler, \& H. Jammes. 2003. Growth hor-mone and milking frequency act differently on goat mammary gland in late lactation. J. Dairy Sci. 86 : 509-510. https://doi.org/10.3168/jds.S0022-0302(03)73629-7

Chen, W.Y., M.H. Weng, S.E. Chen, H.C. Peh, W.B. Liu, T.C. Yu, M.T. Chen, H. Naganata, \& C.J. Chang. 2007. Profile of gelatinolytic capacity in raw goat milk and the implication for milk quality. J. Dairy Sci. 90: 4954-4965. https://doi. org/10.3168/jds.2007-0366

De Vries, L.D., H. Dover, T. Casey, M.J. VandeHaar, \& K. Plaut. 2010. Characterization of mammary stromal remodeling during the dry period. J. Dairy Sci. 93: 2433-2443. https://doi.org/10.3168/jds.2009-2764

Ferneborg, S., \& K. Svennersten-Sjaunja. 2015. The effct of pulsation ratio on teat condition, milk somatic cell count and productivity in dairy cows in automatic milking. J. Dairy Res. 82: 453-459. https://doi.org/10.1017/ S0022029915000515 
Ferranti, P., M.V. Traisci, G. Picariello, A. Nasi, V. Boschi, M. Siervo, C. Falconi, L. Chianese, \& F. Addeo. 2004. Casein proteolysis in human milk : tracing the pattern of casein breakdown and the formation of potential abioactive peptides. J. Dairy Res. 71: 74-87. https://doi.org/10.1017/ S0022029903006599

Gifre-Renom, L., J.V. Carratalá, S. Parés, L. Sánchez-García, N. Ferrer-Miralles, A. Villaverde, A. Bach, Elena GarciaFruitós, \& Anna Arís. 2020. Potential of MMP-9 based nanoparticles at optimizing the cow dry period: pulling apart the effects of MMP-9 and nanoparticles. Sci. Rep. 10: 11299. https://doi.org/10.1038/s41598-020-67176-2

Ho, C.H., C.J. Chang, W.B. Liu, H.C. Peh, S.E. Chen, H.Y. Chen, T.H. Ho, M.T. Chen, \& H. Nagahata. 2010. In situ generation of milk protein derived peptides in drying-off cows. J. Dairy Res. 77: 487-497. https://doi.org/10.1017/ S0022029910000634

Hurley, W.L. \& P.K. Theil. 2011. Perspectives on immunoglobulins in colostrum and milk. Nutrients. 3: 442-474. https:// doi.org/10.3390/nu3040442

Hynes, R.O. 2009. The extracellular matrix: Not just pretty fibrils. Science. 326: 1216-1219. https://doi.org/10.1126/ science.1176009

Khokha, R., \& Z. Werb. 2011. Mammary gland reprogramming: metalloproteinases couple form with function. Cold Spring Harb. Perspect. Biol. 3: a004333. https://doi.org/10.1101/ cshperspect.a004333

Laemmli, U.K. 1970. Cleavage of structural proteins during assembly of the head bacteriophage T4. Nature 227:680-685. https://doi.org/10.1038/227680a0

Li, H., H. Zheng, L. Li, X. Shen, W. Zang, \& Y. Sun. 2016. The effects of matrix metalloproteinase- 9 on dairy goat mastitis and cell survival of goat mammary epithelial cells. Plos one. 11: e0160989. https://doi.org/10.1371/journal. pone.0160989

Maldonado, M., \& J. Nam. 2013. The role of changes in extracellular matrix of cartilage in the presence of inflammation on the pathology of osteoarthritis. BioMed Res. Int. 2013: 284873. https://doi.org/10.1155/2013/284873

Mein, G.A. 2012. The role of the milking machine in mastitis control. Vet. Clin. N. Am. Food Anim. Pract. 28: 307-320. https://doi.org/10.1016/j.cvfa.2012.03.004

Miller, N., L. Delbecchi, D. Petitclerc, G.F. Wagner, B.G. Talbot, \& P. Lacasse. 2006. Effect of stage of lactation and parity on mammary gland cell renewal. J. Dairy Sci. 89: 4669-4677. https://doi.org/10.3168/jds.S0022-0302(06)72517-6

Nielsen, S.S. 2002. Plasmin system and microbial proteases in milk: characteristics, roles, and relationship. J. Agric. Food Chem. 50: 6628-6634. https://doi.org/10.1021/jf0201881

Osteras, O., O. Ronningen, L. Sandvik, \& S. Waage. 1995. Field studies show associations between pulsator characteristics and udder health. J. Dairy Res. 62:1-13. https://doi. org/10.1017/S0022029900033628

Penry, J.F., J. Upton, S. Leonardi, P.D. Thompson, \& D.J. Reinemann. 2018. A method for assessing teatcup liner performance during the peak milk flow period. J. Dairy Sci. 101: 649-660. https://doi.org/10.3168/jds.2017-12942

Pezeshki, A., A.V. Capuco, B. De Spiegeleer, L. Peelman, M. Stevens, R.J. Collier, \& C. Burvenich. 2010. An integrated view on how the management of the dry period length of lactating cows could affect mammary biology and defense. J. Anim. Physiol. Anim. Nutr. 94: e7-e30. https://doi. org/10.1111/j.1439-0396.2010.00991.x

Piamya, P., A. Tiantong, S.E. Chen, W.B. Liu, C. Yu, H. Nagahata, \& C.J. Chang. 2015. Fingerprinting of gelatinase subtypes for different topographic regions on nonretaining placenta of Holstein cows. Animal. 9: 490-499. https://doi.org/10.1017/S1751731114002420

Raimondo, R.F.S., F.B. Brandespim, A.P. M. Prina, S.I. Miyashiro, J.P.E. Saut, C.S. Mori, F.C. Ponliani, \& E.H.
Birgel Junior. 2013. Dynamic in the concentration of whey proteins in the mammary secretion of goats during the dry period. Small Ruminant Res. 113: 239-246. https://doi. org/10.1016/j.smallrumres.2013.03.006

R Core Team. 2018. R: A language and environment for statistical computing. R Foundation for Statistical Computing, Vienna, Austria. http://www.R-project.org/.

Romero, G., C. Peris, G. C. Fthenakis, \& J. R. Diaz. 2020. Effects of machine milking on udder health in dairy ewes. Small Ruminant Res. 188: 106096. https://doi.org/10.1016/j. smallrumres.2020.106096

Sorensen, M.T., J.V. Norgaard, P.K. Theil, M. Vestergaard, \& K. Sejrsen. 2006. Cell turnover and activity in mammary tissue during lactation and the dry period in dairy cows. J. Dairy Sci. 89: 4632-4639. https://doi.org/10.3168/jds. S0022-0302(06)72513-9

Stelwagen, K., \& K. Singh. 2014. The role of tight junctions in mammary gland function. J. Mammary Gland Biol. Neoplasia. 19: 131-138. https://doi.org/10.1007/ s10911-013-9309-1

Tiantong, A., \& D.A. Mwabena. 2019. The effects of parity on protective protein components and MMP proteolytic activity of mammary secretion during involution in tropical dairy cows. Adv. Anim. Vet. Sci. 7: 914-920. https://doi. org/10.17582/journal.aavs/2019/7.10.914.920

Tiantong, A, H.Y. Peng, S.E. Chen, P. Piamya, W.B. Liu, M.T. Chen, C. Yu, H. Nagahata, \& C.J. Chang. 2015a. Intramammary infusion of an Enterococcus faecium SF68 preparation promoted the involution of drying off Holstein cows partly related to neutrophil-associated matrix metalloproteinase 9. Anim. Sci. J. 86: 111-119. https:// doi.org/10.1111/asj.12243

Tiantong, A, P. Piamya, S.E. Chen, W.B. Liu, F.Y. Chang, P.C. Lin, H. Nagahata, \& C.J. Chang. 2015b. Systemic and local bactericidal potentiality in late lactation Holstein-Friesian cows following a combined antibiotics and Enterococcus faecium SF68 dry-cow treatment. Jpn. J. Vet. Res. 63: 139-150.

Tromas, C.V., D.K. Force, D.H. Bremel, \& S. Strasser. 1991. Effects of pulsation ratio, pulsation rate, and teatcup liner design on milking rate and milk production. J. Dairy Sci. 74: 1234-1249. https://doi.org/10.3168/jds. S0022-0302(91)78280-5

Upton, J, J.F. Penry, M.D. Rasmussen, P.D. Thompson, \& D.J. Reinemann. 2016. Effect of pulsation rest phase duration on teat end congestion. J. Dairy Sci. 99: 3958-3965. https:// doi.org/10.3168/jds.2015-10466

Weng, M.H., T.C. Yu, S.E. Chen, H.C. Peh, W.B. Liu, M.T. Chen, H. Nagahata, \& C.J. Chang. 2008. Regional accretion of gelatinase $\mathrm{B}$ in mammary gland during gradual and acute involution of dairy animals. J. Dairy Res. 75: 202-210. https://doi.org/10.1017/S0022029908003130

Wenz, J.R, L.K. Fox, F.J. Muller, M. Rinaldi, R. Zeng, \& D.D. Bannerman. 2010. Factors associated with concentrations of select cytokine and acute phase proteins in dairy cows with naturally occurring clinical mastitis. J. Dairy Sci. 93: 2458-2470. https://doi.org/10.3168/jds.2009-2819

Yu, T.C., C.J. Chang, C.H. Ho, H.C. Peh, S.E. Chen, W.B. Liu, H.Y. Peng, P. Piamya, M.T. Chen, \& H. Nagahata. 2011. Modifications of the defense and remodeling functionalities of bovine neutrophils inside the mammary gland of milk stasis cows received a commercial dry-cow treatment. Vet. Immunol. Immunopathol. 144: 210-219. https:// doi.org/10.1016/j.vetimm.2011.09.006

Yu, T.C, S.E. Chen, T.H. Ho, H.C. Peh, W.B. Liu, A. Tiantong, H. Nagahata, \& C. J. Chang. 2012 Involvement of TNF- $\alpha$ and MAPK pathway in the intramammary MMP-9 release via degranulation of cow neutrophils during acute mammary gland involution. Vet. Immunol. Immunopathol. 147: 161:169. https://doi.org/doi:10.1016/j.vetimm.2012.04.011 